\title{
MODEL PELAYANAN BARANG IMPOR MELALUI KARGO UDARA (Tinjauan dari Empat Aspek)
}

\author{
*Mohamad Adam Saputra ${ }^{1}$, Ryan Firdiansyah Suryawan², Naik Henokh Parmenas ${ }^{3}$ \\ 1,2 Sekolah Tinggi Penerbangan Aviasi, Jakarta Barat, DKI, Jakarta \\ ${ }^{3}$ Institut Teknologi dan Bisnis Kalbis, Jakarta, Indonesia \\ *Email Korespondensi: \\ ryan.firdiansyah.1979@gmail.com
}

\section{ARTIKEL INFORMASI}

Diterima:

25 Desember 2021

Direvisi:

12 Januari 2022

Dipublikasi:

30 Januari 2022

\begin{abstract}
ABSTRAK
Tujuan Penelitian ini adalah untuk mengetahui pelayanan kargo udara ditinjau dari empat aspek yaitu sarana prasarana, tenaga kerja, prosedur kerja dan pelaksanaan kegiatan, pelayanan yang dapat memberikan jaminan kepuasan kepada para pelanggan sebagaimana perusahaan harus lebih mengedepankan kualitas pelayanan dan fasilitas penunjang pelayanan agar kegiatan pelayanan optimal dan pelanggan puas terhadap hasil yang telah diperoleh. Dalam penelitian ini metode yang digunakan adalah kualitatif observasi lapangan berdasarkan pengumpulkan data-data terkait pelayanan dan penanganan impor barang. Hasil pada pengamatan dari empat aspek yaitu sarana prasarana, tenaga kerja, prosedur kerja dan pelaksanaan kegiatan, belum cukup optimal dikarenakan prasarana fasilitas masih kurang untuk kegiatan pelayanan namun untuk prosedur dalam pelayanan sudah cukup baik.
\end{abstract}

Kata Kunci: Pelayanan, Sarana Prasarana, Prosedur Kerja, Pelaksanaan Kegiatan, Kargo Udara

\section{PENDAHULUAN}

Saat ini dunia bisnis berkembang semakin meningkat sebanding dalam meningkatnya permintaan masyarakat Indonesia terhadap produk dalam mencukupi kebutuhan. Besarnya kebutuhan masyarakat pada jasa pengiriman barang, merupakan peluang bagi bisnis itu tersendiri dan bagi para pelaku bisnis ekspedisi. Hal ini bisa terlihat dari banyaknya jumlah perusahaan yang melebarkan sayapnya di bidang pengiriman barang. Erwin \& Tumpal (2017:8) di Indonesia sendiri, industri layanan pengiriman barang merupakan prospek usaha yang tingkat pertumbuhan ekonominya bertumbuh pesat dari tahun ke tahun. Bukan hanya dalam perusahaan swasta, tetapi perusahaan yang milik negara juga turut serta berbenah diri dan menerapkan sejumlah kemudahan didalam layanan jasa pengiriman barang. Tantangan perekonomian masa depan yang semakin kompetitif salah satu masalah terletak pada peningkatan mutu dan produktivitas (kinerja) pelayanan yang dapat memberikan jaminan kepuasan kepada para pelanggan. Masalah-masalah inilah yang menjadi salah satu kunci untuk dapat memenangkan suatu persaingan dalam sistem perekonomian suatu bangsa. Indonesia merupakan negara 
pengimpor yang cukup besar terutama untuk industri yang dapat memajukan perekonomian Indonesia. Meningkatnya intensitas persaingan dan jumlah pesaing menuntut perusahaan untuk selalu memperhatikan kebutuhan dan keinginan konsumen serta berusaha memenuhi harapan konsumen dengan cara memberikan pelayanan yang lebih memuaskan.

Ekspor dan Impor merupakan kegiatan yang mendukung terlaksananya perdagangan antar negara. Pengertian dari ekspor sendiri adalah Proses pengiriman barang dari satu negara ke negara lain. Lawan dari kegiatan ekspor adalah impor. Impor adalah proses transportasi penerimaan barang dari suau Negara lain, umumnya pada proses perdagangan. Bisnis Freight Forwarding adalah salah satu bisnis yang menyediakan layanan untuk Ekspor dan Impor barang. Dalam PM 130 TAHUN 2016 Perubahan Keempat atas Peraturan Menteri Perhubungan Nomor PM 74 Tahun 2015 tentang Penyelenggaraan dan Pengusahaan Jasa Pengurusan Transportasi, yang dimaksud dengan Jasa Freight Forwarding adalah sebagai berikut :

"Usaha yang ditujukan untuk mewakili kepentingan pemilik barang, untuk mengurus semua kegiatan yang diperlukan bagi terlaksananya pengiriman dan penerimaan barang melalui transportasi darat, laut dan udara yang dapat 2 mencakup kegiatan penerimaan, penyimpanan, sortasi, pengepakan, penandaan pengukuran, penimbangan, pengurusan penyelesaian dokumen, penerbitan dokumen angkutan, klaim asuransi atas pengiriman barang serta penyelesaian tagihan dan biaya-biaya lainnya berkenaan dengan pengiriman barangbarang tersebut sampai dengan diterimanya barang oleh yang berhak menerimanya" Dalam menerapkan prosedur pelayanan impor, dibutuhkannya personil atau tenaga kerja yang berpengetahuan dan ditunjangnya dengan sarana dan prasarana yang memadai dan mempermudah proses dalam pelayanan dan penanganan. Dalam kegiatan operasional atau lapangan ditemukan beberapa masalah seprti terjadinya mati listrik, perubahan alamat (redress manifest) dan menunggunya release letter of credit (L/C) karena membutuhkan waktu yang cukup lama hingga berjalannya impor menjadi lama. Dari uraian di atas terdapat fenomena dari sisi sarana prasarana, tenaga kerja, prosedur kerja, serta pelaksanaan kegiatan berkaitan dengan pelayanan barang impor kargo udara dengan mengambil data di perusahaan kargo yang ada di Jakarta, Indonesia.

\section{KAJIAN PUSTAKA}

Transportasi merupakan salah satu matai rantai yang sangat vital dalam suatu kegiatan perekonomian pada suatu negara. Tanpa adanya transportasi sebagai sarana penunjang maka tidak dapat diharapkan tercapainya suatu hasil yang maksimum dan memuaskan bagi perkembangan ekonomi negara tersebut Terkait dengan pentingnya fungsi transportasi dalam perekonomian masyarakat maka muncul banyak perusahaan freight forwarding, yang salah satu jasa yang ditawarkan adalah transportasi pengiriman barang (Undang-Undang Nomor 17 Tahun 2008). Dalam Undang-Undang Kementrian Perhubungan 53 No 12 tahun 2017 berisi Kargo adalah setiap barang yang diangkut oleh pesawat udara selain benda pos, barang kebutuhan pesawat selama penerbangan yang habis pakai, dan bagasi yang tidak ada pemiliknya atau bagasi yang salah penanganan. Menurut Warpani (2017:95) Kargo atau Cargo adalah semua yang dikirim melalui udara, laut, dan darat yang biasanya untuk diperdagangkan. Baik antar Wilayah/Kota di dalam negeri hingga antar Negara (internasional) yang dikenal dengan istilah Ekspor-Impor. Secara umum ada tiga jenis kargo yang dapat diklasifikasikan sebagai berikut:

a. General Cargo, General cargo adalah kargo atau barang yang pada umumnya memiliki sifat yang tidak membahayakan, tidak mudah rusak, busuk atau mati, barang yang tidak memerlukan penanganan khusus, persyaratan pengangkutan memenuhi ketentuan yang berlaku, serta ukuran dan beratnya dapat ditampung ke dalam ruangan (compartement) pesawat udara, sehingga barang-barang tersebut dapat diberangkatkan seperti garmen, spare part, elektronik.

b. Special Cargo, Special cargo adalah kargo atau barang-barang yang memerlukan penanganan khusus baik dalam penerimaan, penyampaian atau pengangkutan. Yang dikategorikan special cargo antara lain:

1) Live Animal (AVI)

2) Human Remain ( HUM )

3) Perishable goods ( PER )

4) Valuable goods ( VAL )

5) Strongly smelling goods

6) Live Human Organ ( LHO ) 
7) Diplomatic Pouch (DIP)

Dokumen utama yang diperlukan mengangkut kargo menurut pasal 1 angka 28 undang-undang no 12009 tentang penerbangan yaitu surat muatan udara yang biasa disebut Airway Bill adlah dokumen berbentuk cetak melalui proses elektronik, atau bentuk lainnnya yang merupakan salah satu bukti adanya perjanjian pengangkutan udara antara pengirim kargo dan pengangkut, dan hak penerima kargo untuk mengambil kargo. Selain itu ada beberapa dokumen pendukung seperti surat keterangan dari dokter hewan, surat izin sertfikasi pengangkutan, surat pembebasan tanggung jawab dan surat pemberitahuan tentang ini. Berikut beberapa jenis dokumen penting dalam kegiatan impor menurut Hamdani dan Haikal (2017:2) :

a. Commercial Invoice, Merupakan dokumen penjualan atau faktur penjualan yang di dalamnya memuat informasi mengenai jenis barang dan harga barang-barang yang telah disepakati antara kedua belah pihak. Informasi yang tercakup dalam dokumen ini ialah :

1) Nama serta alamat importir dan eksportir

2) Nomor dan tanggal surat pesanan

3) Nomor dan tanggal pembukaan L/C dan nama bank L/C

4) Jumlah barang

5) Harga satuan (jika ada) dan harga total sesuai kesepakatan

6) Jenis pembayaran

7) Nama kapal pengangkut

8) Nama pelabuhan muat serta tanggal keberangkatan

9) Nama pelabuhan bongkar

b. AirWay bill, Adalah dokumen pengapalan yang memiliki peranan atas kepemilikan barang. Bill of lading di keluarkan pada saat barang sudah di muat diatas kapal. Memiliki fungsi sebagai (1) Bukti tanda penerimaan barang (2) tanda kontrak pengangkutan (3) bukti kepemilikan barang. AirWay bill berisikan informasi lengkap mengenai nama pengirim, nama kapal, data muatan, pelabuhan muat, pelabuhan bongkar, rincian freight dan pembayarannya, nama penerima.

c. Packing List, Dokumen pengemasan yang di dalamnya berisikan informasi seperti jumlah barang, nama barang hingga berat bersih dan kotor barang yang terdapat dalam setiap peti / karung. Fungsinya untuk memudahkan pejabat Bea dan Cukai melakukan pemeriksaan.

d. Polis Asuransi, yang berisikan perjanjian atau kontrak asuransi mengenai pertanggungjawaban atas barangbarang yang di kirim.

e. Surat Keterangan Asal, Surat atau dokumen yang menyatakan kejelasan infromasi dari mana barang berasal. Dengan adanya dokumen ini, importir tahu jelas dan pasti bahwasannya barang yang diimpornya benar berasal dari dan diproduksi di negara eksportir. Digunakan untuk memperoleh fasilitas bea masuk.

f. Pemberitahuan Impor Barang (PIB), Salah satu dokumen kepabeanan untuk melakukan kegiatan impor barang yanng akan diberitahukan atau dikirimkan kepada Bea dan Cukai. PIB digunakan untuk dasar pengeluaran barang. Hal- hal yang tercantum dalam PIB di antaranya :

1) Jenis impor: untuk dipakai, sementara, lainnya.

2) Jenis PIB : bayar, keringanan, bebas dan lain-lain.

3) Nama dan alamat pemasok.

4) Nama dan alamat importir beserta identitasnya.

5) Status importir, importir umum, agen tunggal dan lain-lain.

6) dentitas pemberitahuan.

7) Nama, tanggal surat ijin Pengusahan Pengurus Jasa Kepabeanan.

8) Cara pengangkutan: laut, udara dan lain-lain.

9) Nama sarana pengangkut: no. Voyage.

10) Nama pelabuhan muat dan bongkar.

11) Nama pelabuhan transit jika barang pindah kapal/pesawat

12) No. Invoice, $L / C$, dan $B / L$.

13) NDPBM (Nilai Dasar Perhitungan Bea Masuk).

14) Harga total FOB, dan nilai CIF 
Prosedur penting dimiliki bagi suatu organisasi agar segala sesuatu dapat dilakukan dapat terlaksana dengan baik. Pada akhirnya prosedur akan menjadi pedoman bagi suatu organisasi dalam menentukan aktivitas apa yang harus dilakukan untuk menjalankan suatu fungsi tertentu. Prosedur adalah rangkaian kegiatan yang telah menjadi pola dan sudah ditentukan dalam melakukan suatu pekerjaan atau aktivitas. Prosedur ialah aspek berarti di dalam melaksanakan tugas dan pekerjaan, baik dalam bidang kegiatan operasional maupun bidang pekerjaan perkantoran. Kata prosedur berasal dari Inggris ialah procedure yakni metode, jalan, ketentuan yang dipakai. Meski begitu kata procedure sudah umum digunakan dalam kosakata bahasa Indonesia yang di tahu dengan prosedur (Pranaswati, 2018:7). Menurut Mulyadi (2016:4) prosedur adalah suatu urutan kegiatan klerikal biasanya melibatkan beberapa orang dalam satu departemen atau lebih, yang dibuat untuk menjamin penanganan secara seragam transaksi perusahaan yang terjadi berulang-ulang. Menurut Rifka R.N menyatakan (2017:75) Prosedur adalah urutan kerja atau kegiatan yang terencana untuk menangani pekerjaan yang berulang dengancara seragam atau terpadu.

Pelayanan menurut Kasmir (2017: 47) adalah tindakan atau perbuatan seseorang atau suatu organisasi untuk memberikan kepuasan kepada pelanggan, sesama karyawan, dan juga pimpinan. Pelayanan (Jasa) Menurut Kotler \& Keller dalam Tjiptono \& Chandra (2016:13) jasa sebagai setiap tindakan atau perbuatan yang dapat ditawarkan oleh suatu pihak kepada pihak lain yang pada dasarnya bersifat intangible (tidak berwujud fisik) dan tidak menghasilkan kepemilikan sesuatu. Menurut Gronroos dalam Tjiptono \& Chandra (2016:13) jasa adalah proses yang terdiri atas serangkaian aktivitas intangible yang biasanya (namun tidak harus selalu) terjadi pada interaksi antara pelanggan dan karyawan jasa.

Banyak variabel yang mempengaruhi kepuasan pelanggan salah satunya adalah fasilitas. Menurut Sulastiyono dalam (Sudaryana, 2020) fasilitas adalah memenuhi kebutuhan tamu berupa perlengkapanperlengkapan fisik sehingga dapat mudah digunakan oleh tamu dalam melaksanakan aktivitasnya. Fasilitas mempengaruhi kepuasan pelanggan karena fasilitas merupakan sesuatu yang membuat pelanggan dapat menikmati manfaat dari produk atau jasa dan memudahkan pelanggan dalam mengerjakan berbagai aktifitasnya. Kemudian, fasilitas disediakan lengkap dan desain yang menarik juga akan membuat pelanggan merasa puas. Fasilitas-fasilitas yang di butuhkan pelanggan dalam menggunakan jasa seperti toilet, parkir, musollah, TV, WiFi dan lain-lain. Fasilitas menjadi salah satu kebutuhan pokok kehidupan manusia. Karena fasilitas menjadi salah satu komponen penting bagi kehidupan, maka perusahaan harus dapat mengelola dengan baik sepanjang hidupnya, sehingga ia dapat selalu berfungsi dengan baik, ekonomis, efisien dan efektif (Aryani Soemitro \& Suprayitno, 2018). Memberikan layanan dan fasilitas berkualitas bersama-sama dapat memberikan hasil dan manfaat bagi bisnis karena kepuasan pelanggan telah terjadi (Baiti, 2018:49).

\section{METODE}

Dalam artikel ini, metode penelitian yang digunakan adalah kualitatif dengan mencari data-data yang dibutuhkan berkaitan dengan tinjauan dari empat aspek yaitu sarana prasarana, tenaga kerja, prosedur kerja dan pelaksanaan kegiatan, melalui observasi terbatas pada perusahaan kargo di Jakarta, wawancara terbatas menyangkut empat aspek di atas dan studi literatur guna mendukung dengan refrensi yang tersedia.

\section{HASIL DAN PEMBAHASAN}

Tinjaun dari empat aspek sarana prasarana, tenaga kerja, prosedur kerja dan pelaksanaan kegiatan dikaitkan dengan proses pelayanan kargo udara bahwa proses Pelayanan barang Impor di perusahaan kargo mampu menangani pengiriman ke dan dari port di seluruh dunia. Agar tetap kompetitif dalam Shipping and Freight Forwarding Market, kami menekankan pada layanan kami yang cepat dan dapat diandalkan untuk memenuhi persyaratan terbaik dari pelanggan kami. berikut proses kerja Air Freight Impor di perusahaan kargo yang di observasi dan di wawancara :

a. Consignee / Customer memberikan informasi bahwa ada shipment impor yang harus dijalankan. Customer memberikan informasi sesuai dengan kebutuhan impor yang akan dikirim.

b. Setelah menerima intruksi atau informasi dari customer, booking ke shipping line luar negeri untuk booking container untuk pengiriman impor dari luar ke Indonesia.

c. Setelah adanya booking ke shipping line, menerima booking confirmation, dan setelah adanya booking confirmation Shipping Line luar negeri akan mengirim PreAlert kepada KTI, lalu bagian Operation mengecek seluruh dokumen/PreAlert yang masuk yang berisi detail informasi mengenai shipment yang dijalankan, berupa shipper, consignee dan deskripsi barang. 
d. Setelah itu KTI akan melakukan proses untuk Bea Cukai Bandara Soekarno Hatta dengan melampirkan PIB (Pemberitahuan Import Barang).

e. Setelah proses bea cukai selesai, beberapa saat barang akan sampai di gudang Airlines Soekarno Hatta Internasional Airport, barang akan dipindahkan dari gudang airlines ke gudang KTI atau langsung dikirim ke gudang customer.

f. Setelah barang berada di gudang KTI, customer akan meminta barang dikeluarkan dari gudang KTI. Dan memastikan bahwa dokumen nya yang menyangkut shipment tersebut telah lengkap. Dan keluar pula biaya sewa gudang dari penyimpanan barang selama di gudang KTI.

g. Setelah barang keluar, bagian Billing akan Print Faktur Pajak yang berisi tentang Pajak Barang tersebut.

$h$. Bagian operation akan menyiapkan invoice yang berisi biaya barang yang dikirim dari shipper dan juga storage, import custom clearance, PIB, dan Air Way Bill, dan juga akan menyiapkan release dokumen yang berisikan HAWB (House Air Way Bill), MAWB (Master Air Way Bill), Commercial Invoice, Packing List, dan Certificate of Origin.

i. Customer menerima document dan invoice.

j. Customer membayar tagihan.

k. Proses selesai.

Dokumen - dokumen yang diperlukan untuk penanganan barang impor. Dalam pelaksanaan penyelesaian impor memerlukan dokumen dokumen yang dapat menunjang pengurusan arus barang, Dokumen - dokumen yang diperlukan antara lain:

a. $\quad$ AWB (Air Way Bill)

Air Way Bill dokumen yang sama dengan B/L yang menjelaskan kepemilikan barang impor yang dilakukan menggunakan jalur udara.

b. Commercial Invoice

Commercial Invoice adalah dokumen yang dibutuhkan untuk proses pengeluran barang, yang berisi resume dari proses jual beli, berisi nama importer, exporter, nama barang, jumlah barang dan nilai barang.

c. $\quad$ Packing List

Packing List adalah dokumen yang berisi deskripsi barang secara rinci meliputi dimensi, berat barang, carrier yang dijelaskan pada packing list.

d. Air Cargo Manifest

Air Cargo Manifest adalah dokumen dalam jasa angkutan yang berisi daftar cargo, penumpang, awak kapal, pesawat udara atau kendaraan lain yang biasa digunakan oleh bea cukai.

f. $\quad \mathrm{COO}$ (Certificate of Origin)

Certificate of Origin adalah dokumen yang menyatakan asal dari barang yang kita impor, biasanya di issue oleh e-commerce (Dept. Perdagangan) di negara asal barang.

g. PIB (Pemberitahuan Impor Barang)

PIB Merupakan dokumen pemberitahuan oleh Importir yang berisi deksripsi barang yang di impor berdasarkan dokumen Impor yang ada. Pada PIB tercantum juga besarnya Bea Masuk dan Pajak yang harus di bayar oleh Importir berdasarkan nilai Invoice yang tercantum pada dokumen.

h. SPPB (Surat Persetujuan Pengeluaran Barang)

SPPB dokumen yang dikeluarkan oleh bea cukai setelah importir melunasi kekurangan pembayaran SPTNP (Surat Penetapan Tarif atau Nilai Pabean), Maka SKP (Sistem Komputerisasi Pelayanan) akan menerbikan SPPB (Surat Persejutuan Pengeluaran Barang).

Pada saat melihat langsung semua dokumen yang digunakan maka sudah lengkap dan sesuai dengan ketentuan yang berlaku maka barang tersebut akan bisa segera diproses. Kendala yang terjadi pada saat pelaksaan pelayanan barang impor Dalam pelaksanaan kegiatan pelayanan barang impor tersebut tentunya tidak lepas dari faktor - faktor yang menghambat, sehingga kelancaran pengurusan barang impor tersebut kurang efektif dan efisien. Adapun faktor yang menghambat antara lain:

a. Generator Listrik

Pada saat pelayanan generator sangat berpengaruh dikarenakan terjadi kendala pada saat kegiatan operasional. Generator listrik sangat penting untuk kegiatan perusahaan. Dalam pengamatan penulis saat terjadinya listrik padam menjadi menghambat pada pelayanan berlangsung.

b. Redress Manifest 
Redress manifest adalah pembetulan atau perubahan pemberitahuan manifest yang telah disampaikan ke kantor pabean yaitu terdapat kesalahan mengenai nomor, merek, ukuran dan jenis kemasan atau peti kemas, terdapat kesalahan mengenai jumlah kemasan atau petikemas serta jumlah barang curah, terdapat kesalahan nama consignee pada manifest, terdapat kesalahan data lainnya atau perubahan pos manifest.

c. Kehilangan Dokumen. Dokumen, sekumpulan surat berharga atau tulisan yang digunakan sebagai bukti atau keterangan. Dalam dunia ekspor impor khususnya freight forwarding dokumen merupakan hal yang sangat penting karena dalam proses kerjanya selalu berkaitan dengan surat surat penting dari instansi terkait. Pada perusahan ini beberapa kasus kehilangan dokumen yang mengakibatkan terhambatnya proses pekerjaan yang berlangsung.

d. Importir yang belum memiliki izin impor, Dalam kegiatan ekspor-impor perizanan merupakan sebuah gerbang utama yang harus dimiliki oleh setiap importir sebelum mendatangkan atau mengirimkan barang dari atau ke daerah pabean. Ada sebagian importir yang kurang memperdulikan atau kurang mendapatkan pemahaman tentang pentingnya perizinan dari kementrian terkait untuk melakukan kegiatan ekspor impor sehingga barang barang tesebut tidak bisa dikeluarkan karena tidak dipenuhinya persyaratan yang diajukan oleh bea cukai.

Dari hasil observasi, wawancara di perusahaaan kargo di Jakarta mengenai empat aspek sarana prasarana yang disediakan belum cukup memadai dan optimal dengan adanya uraian di atas. Diharapkan dari adanya kendala ini perusahaan wajib memilikinya dan mengevaluasinya agar pada saat kegiatan pelayanan tidak menghambat operasional, Prasarana untuk menunjang kegiatan operasional, dari tenaga kerja dengan hasil karyawan harus memelihara sebaik mungkin agar prasarana yang disediakan dapat beroperasi dengan baik dan dapat digunakan pada saat kegiatan opersional berlangsung, Prosedur kerja dijalankan dengan baik dan harus lebih memliki cara efektif dalam menghadapi kendala tersebut serta memberikan pemahaman yang lebih dekat lagi kepada costumer. Tenaga kerja bekerja sesuai dengan uraian pekerjaan yang berkaitan dengan pelayanan kargo udara.

\section{KESIMPULAN DAN SARAN}

Sarana dan Prasarana yang tesedia pada perusahaan kargo dalam menunjang pelayanan kargo udara belum sangat baik serta belum memadai sehingga dapat menyebabkan terhambatnya proses kegiatan operasional karyawan. Tenaga kerja yang bekerja dengan sangat profesional dan sesuai dengan peraturan yang sudah ditetapkan. Prosedur kerja sangat membantu dan mempermudah serta menjadi acuan bagi dalam melaksanakan kegiatan operasional. Persyaratan yang digunakan sebelum dilakukannya kegiatan operasional sudah terlaksanakan dengan baik sehingga kegiatan operasional berjalan dengan baik dan lancar dan sudah dilakukan sesuai undang-undang yang berlaku yaitu, Peraturan Menteri Keuangan No.182 / PMK.04 / 2016 tentang Ketentuan Impor Barang Kiriman. Hambatan yang terjadi dalam proses Pelayanan Barang Impor yang dilakukan yaitu, mulai dari mekanisme prasarana pada pelayanan impor barang yang harus diperbaiki sehingga tidak lagi menjadi penghambat proses pelayanan barang dari pembuatan dokumen untuk costumer sampai kegiatan operasional perusahaan dan keterlambatan proses pengeluaran barang di tempat penimbunan serta notul yang timbul akibat kelalaian pengecekan dokumen impor. Dalam ini upaya yang harus diatasi adalah dengan meakukan pengadaan barang dan memilih eksportir yang baik dan responsif, melakukan komunikasi kepada customer dan melakukan pengecekan ulang atas dokumen-dokumen impor.

\section{Daftar Pustaka}

Baiti, M. (2018). Pengaruh lokasi, harga dan fasilitas hotel terhadap keputusan menginap pelanggan.

Erwin., T. J. (2017). Kontribusi Kualitas Jasa, Kepercayaan dan Kepuasan Konsumen Dalam Menciptakan Loyalitas Konsumen. Jurnal Manajemen. Vol.13(2): 85-191.

Hamdani, \& \& Haikal, M. (2017). Seluk Beluk Perdagangan Ekspor - impor (jilid I). Jakarta: Bushindo.

Kashmir. (2017). Customer Service Excellent. Depok: PT Raja Grafindo Persada.

Mulyadi. (2016). Sistem Informasi Akuntansi. Jakarta: Salemba Empat.

Perhubungan, P. M. (No 130 2016).

Prasnawati. (2018). Prosedur Impor Bahan Baku Pada PT. Hanil Indonesia di Boyolali. https://digilib.uns.ac.id/dokumen/detail/62614/Prosedur-Impor-Bahan-Baku-Pada-PT-Hanil-Indonesia-di-Boyolali. 
Soemitro, H. S. (2018). “Preliminary Reflexion on Basic Principle of Infrastructure Asset Management,” J. Manejemen Aset Infrastruktur Fasilitas, vol. 2, no. 1,.

Sudaryana. (2020). Pengaruh kualitas pelayanan, kepercayaan dan harga terhadap kepuasan konsumen pada kantor pos Indonesia (persero) Kota Tangerang. Jurnal Management Review Vol 4, No. 1. ISSN-E 2579-812X.

Sukmadian, C. (2017). PROSEDUR PENGAJUAN KLIM DANA PENSIUN PADA PT.TASPEN (PERSERO) KANTOR CABANG PURWOKERTO. Purwokerto: http://repository.ump.ac.id/4558/.

Warpani, S. P. (2017). Ekonomi Perangkutan. Kementerian Pemberdayaan Perempuan dan Perlindungan Anak. , Undang-Undang Republik Indonesia Nomor 1 Tahun 2009 Tentang Penerbangan ,Undang-Undang Republik Indonesia Nomor 13 Tahum 2003 Tentang Ketenagakerjaan , Undang-Undang kementrian Perhubungan 53 no 12 tahun 2017 , Undang-Undang kementrian Perhubungan Nomor 130 Tahun 2016 ,Undang-Undang kementrian Perhubungan Nomor 74 Tahun 2015 ,Undang-Undang kementrian Perhubungan Nomor 17 Tahun 2018 